\title{
PROGRAM BRIKET BIOARANG SEBAGAI PENGGANTI BAHAN BAKAR ALTERNATIF BAGI MASYARAKAT DESA PANDOWAN
}

\author{
Sumaryati dan mahasiswa KKN Reguler 61 divisi XI.A \\ Universitas Ahmad Dahlan Yogyakarta
}

\begin{abstract}
Abstrak
Desa Pandowan terletak di Kecamatan Galur, Kabupaten Kulon Progo, Daerah Istimewa Yogyakarta. Desa Pandowan sebelah timur berbatasan dengan Desa Brosot, sebelah selatan berbatasan dengan Desa Nomporejo dan Karangsewu, sebelah barat berbatasan dengan Desa Tirtorahayu, sedangkan sebelah utara berbatasan dengan Desa Brosot dan Kecamatan Lendah. Salah satu kekayaan yang dimiliki masyarakat Desa Pandowan, Galur, Kulon Progo, Yogyakarta adalah lahan sawah yang luas, karena mayoritas penduduknya berprofesi sebagai petani. Setelah musim panen, banyak limbah dari hasil penggilingan padi yang menumpuk dan tidak dimanfaatkan dengan maksimal. Limbah sekam biasanya hanya dimanfaatkan untuk pembakaran batu bata. Karena banyaknya tumpukan limbah sekam tersebut dan kurangnya pengetahuan masyarakat akan pengolahan limbah sekam padi, maka mahasiswa KKN UAD membuat program kerja yangdifokuskan untuk menumbuhkan rasa kepedulian masyarakat terhadap pengolahan sekam padi untuk menghasilkan briket bioarang sebagai bahan bakar alternatif dan keterampilan untuk mengubah limbah sekam padi menjadi sesuatu yang bernilai ekonomi.
\end{abstract}

Katakunci: briket bioarang, sekam padi, Desa Pandowan

\begin{abstract}
PandowanVillage is located in Galur Sub District, KulonprogoRegency, Special Region of Yogyakarta. Theeast side ofPandowan Village is bordered with Brosot Village, the south side is bordered with Nomporejo Village and Karangsewu, the west side is bordered with Tirtorahayu Village, while the north side is brodered with Brosot Village and Lendah Sub District. One of community's assets in Pandowan Village, Galur, KulonProgo, Yogyakarta is thewide rice field because most of the residents are farmers. After harvest season, there are many piled upwastes from rice millers that are not used maximally. Husk wastes are usually only used for brick kilns. Because lots of husk waste pile ups, thus the studentsof KKN UAD arrange a program that is focused on emerging the community's sense in concerning of paddy husk wastes to produce briketbioarangas an alternative fuel and skill to transform paddy husk wastes to be more economically valued.
\end{abstract}

Keywords: briketbioarang, paddy husk, Pandowan Village 
Diterbitkan oleh Lembaga Pengabdian kepada Masyarakat

Universitas Ahmad Dahlan Yogyakarta

\section{A. PENDAHULUAN}

Energi merupakan suatu kompenen kebutuhan hidup yang sangat penting. Energi tidak dapat diciptakan dan tidak dapat dimusnahkan melainkan hanya dapat diubah kebentuk lain yang lebih bermanfaat guna untuk memenuhi kebutuhan hidup. Ketersediaan energi di bumi semakin hari semakin sedikit, hal tersebut merupakan masalah besar yang dihadapi manusia dewasa ini.

Apabila hal tersebut dibiarkan secara terus menerus, tanpa memperhitungkan sumber cadangan minyak bumi yang tersisa, maka manusia akan kekurangan sumber energi. Akibatnya manusia akan kesulitan mendapatkan bahan bakar minyak bumi. Oleh karena itu perlu dipikirkan bahan alternatif baru penghasil energi kalor yang lain. Pemanfaatan bahan organik sebagi pengganti penghasil kalor merupakan hal yang tepat. Karena bahan organik dipastikan selalu dapat diproduksi ulang oleh manusia.

Bahan-bahan organik dapat ditemukan di lingkungan sekitar, misalnya pada lahanlahan subur dan lahan pertanian. Lahan pertanian masih banyak ditemukan di area pedesaan. Salah satu desa yang memiliki area persawahan yang luas adalah Desa Pandowan. Desa Pandowan memiliki penduduk yang mayoritas bermata pencaharian sebagai petani. Kebanyakan lahan pertanian di Desa Pandowan ditanami dengan tanaman pangan dan didominasi oleh padi, karena makanan pokok masyarakat Indonesia adalah beras. Beras diperoleh dari hasil pemisahan antara beras dan kulit beras. Hasil buangan dari proses tersebut adalah kulit beras yang biasa dikenal sebagai sekam padi. Apabila limbah pertanian sekam padi tersebut dapat dimanfaatkan sebagai penghasil kalor, maka masyarakat Pandowan dapat lebih menghemat penggunaan minyak bumi dan gas alam sebagai bahan bakar.

Beberapa permasalahan yang ditemukan di Desa Pandowan yaitu: 1). Banyaknya tumpukan limbah sekam saat panen padi, 2). Kurangnya pengetahuan masyarakat akan pengolahan limbah sekam padi yang biasanya hanya dimanfaatkan untuk pembakaran batu bata. Masyarakat turut berperan serta dalam pengolahan sekam padi untuk menghasilkan bahan bakar bioarang sebagai bahan bakar alternatif. Tanpa adanya peran dari masyarakat setempat program yang telah direncanakan tersebut tidak akan berjalan dan hanya akan siasia.

Produksi padi dalam jumlah besar akan menghasilkan sekam padi yang merupakan salah satu bentuk limbah pertanian yang selama ini hanya digunakan sebagai media tanam atau dibuang dan dibakar sebagai sampah. Sebagai bahan biomassa, arang sekam padi merupakan sumber karbon potensial yang dapat dimanfaatkan sebagai bahan bakar dalam skala besar sehingga dapat menjadi salah satu sumber energi alternatif pengganti bahan bakar minyak (BBM)/fosil (Yuliah, 2017).

Briket adalah bahan bakar padat yang dapat digunakan sebagai sumber energi alternatif yang mempunyai bentuk tertentu. Pemilihan proses pembriketan tentunya harus mengacu pada segmen pasar agar di capai nilai ekonomi, teknis dan lingkungan yang optimal. Pembriketan bertujuan untuk memperoleh suatu bahan bahar berkualitas yang dapat digunakan untuk semua sektor sebagai sumber energi pengganti (Himawanto, 2003).

Sumber energi alternatif ini dapat memberikan kontribusi terhadap bauran energi primer sebagai pengganti batubara apabila diolah secara optimal. Pengolahan arang sekam 
padi menjadi briket merupakan salah satu cara pengemasan sekam padi yang efektif. Briket arang sekam padi dapat menyimpan energi kalor rata-rata sebesar $4384.043 \mathrm{~kJ} / \mathrm{kg}$ (Yuliah, 2017).

Berdasarkan permasalahan yang ada, dan kurangnya pengetahuan masyarakat akan pengolahan limbah sekam padi, maka ditetapkan tujuan program KKN ini adalah untuk memberdayakan masyarakat Desa Pandowan serta menumbuhkan rasa kepedulian masyarakat terhadap pengolahan sekam padi untuk menghasilkan briket bioarang sebagai bahan bakar alternatif dan keterampilan untuk mengubah limbah sekam padi menjadi sesuatu yang bernilai ekonomi.

\section{B. METODE PELAKSANAAN}

Untuk mencapai tujuan yang diharapkan, program KKN di Desa Pandowan dilakukan dengan pemberdayaan masyarakat melalui sosialisasi, persiapan bahan dan alat utuk pembuatan briket, dan mempraktekkan pembuatan briket. Ringkasan metode pelaksanaan tersaji pada table 1 .

Tabel 1. Program, Kegiatan dan Mahasiswa yang terlibat

\begin{tabular}{|c|c|c|c|c|}
\hline No & Program & Kegiatan & JKEM & $\begin{array}{c}\text { Mahasiswa yang } \\
\text { terlibat }\end{array}$ \\
\hline \multirow[t]{3}{*}{1} & \multirow[t]{3}{*}{ Sosialisasi } & Pengenalan limbah sekam & $3 \times 100 "$ & \multirow[t]{3}{*}{ unit } \\
\hline & & Dampak limbah sekam & $3 \times 100 ”$ & \\
\hline & & $\begin{array}{l}\text { Pengetahuan tentang cara } \\
\text { pembuatan briket bioarang } \\
\text { melalui video }\end{array}$ & $3 \times 100 "$ & \\
\hline 2 & Persiapan & $\begin{array}{l}\text { Persiapan alat dan bahan } \\
\text { untuk membuat briket } \\
\text { bioarang }\end{array}$ & $3 \times 100 "$ & unit \\
\hline \multirow[t]{4}{*}{3} & \multirow[t]{4}{*}{ Praktik } & $\begin{array}{l}\text { Pembuatan briket bioarang } \\
\text { untuk bapak-bapak }\end{array}$ & $3 \times 100 "$ & \multirow[t]{4}{*}{ unit } \\
\hline & & $\begin{array}{l}\text { Praktek pembuatan briket } \\
\text { bioarang untuk ibu-ibu }\end{array}$ & $3 \times 100 ”$ & \\
\hline & & Uji coba briket bioarang I & $3 \times 100 "$ & \\
\hline & & Uji coba briket bioarang 2 & $3 \times 100 ”$ & \\
\hline
\end{tabular}

Proses Sosialisasi Briket Bioarang dilaksanakan pada tanggal 11 Februari 2017 dibalai desa Pandowan, Galur, Kulon Progo. Kegiatan ini dilakukan bekerja sama dengan Dosen dari Universitas Ahmad Dahlan, Fakultas Kesehatan Masyarakat yaitu Dr. Surahma Asti Mulasari, S.Si., M.Kes. sebagai pemateri. Masyarakat sangat antusias saat proses sosialisai yang disampaikan, hal itu dapat diketahui dengan lebih aktifnya masyarakat dalam bertanya kepada pemateri terkait hal-hal yang sebelumnya tidak mereka ketahui.

Alat-alat yang digunakan pada proses pembuatan briket bioarang yaitu pipa dengan diameter $8 \mathrm{~cm}$ yang digunakan sebagai cetakan untuk bioarang, kompor dan panci untuk 
Diterbitkan oleh Lembaga Pengabdian kepada Masyarakat

Universitas Ahmad Dahlan Yogyakarta

tempat memanaskan tepung kanji, pengaduk, seng yang diberi lubang-lubang sebagai tempat pembakaran, saringan, alat penumbuk, dan ember plastik. Bahan-bahan yang diperlukan yaitu sekam padi, tepung kanji, daun-daun kering sebagai bahan untuk pembakaran, dan air.

Proses Pembuatan Bioarang. Langkah pertama yang dilakukan yaitu pembakaran sekam padi dengan alat menggunakan alat pembakaran yang sudah dibuat dari seng dengan lubang-lubang kecil di sekelilingnya. Sekam padi dipanaskan dengan uap sampai warnanya berubah menjadi hitam. Setelah sekam padi berubah warna dilakukan proses penumbukan agar sekam menjadi halus dan mudah di cetak. Sebelum proses pencetakan, sekam padi yang sudah halus diberikan sedikit tepung kanji yang sebelumnya sudah masak agar sekam yang akan dicetak dapat merekat dengan mudah. Selanjutnya sekam padi yang sudah di cetak dikeringkan dibawah sinar matahari 2-3 hari. Setelah briket bioarang kering maka langsung diuji cobakan untuk pembakaran.

\section{HASIL, PEMBAHASAN DAN DAMPAK}

Gambar aktivitas mahasiswa KKN UAD dan masyarakat Padukuhan 2 Desa Pandowan dalam program kepedulian masyarakat terhadap lingkungan tersaji pada gambar 1, 2, 3 dan 4.

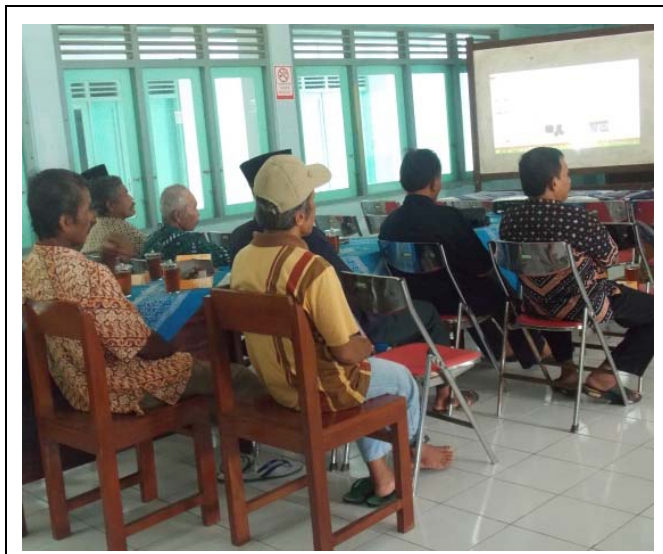

Gambar 1. Pemberian informasi tentang pemanfaatan limbah sekam untuk masyarakat yang tinggal di Padukuhan 2 Desa Pandowan.

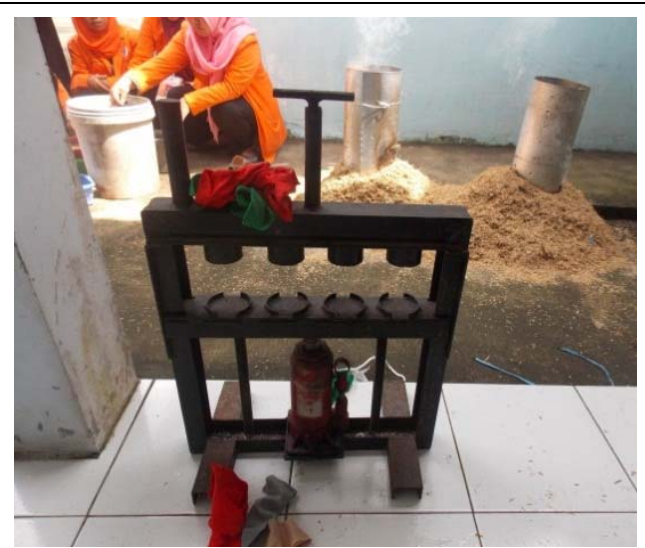

Gambar 2. Persiapan alat dan bahan untuk membuat briket bioarang 


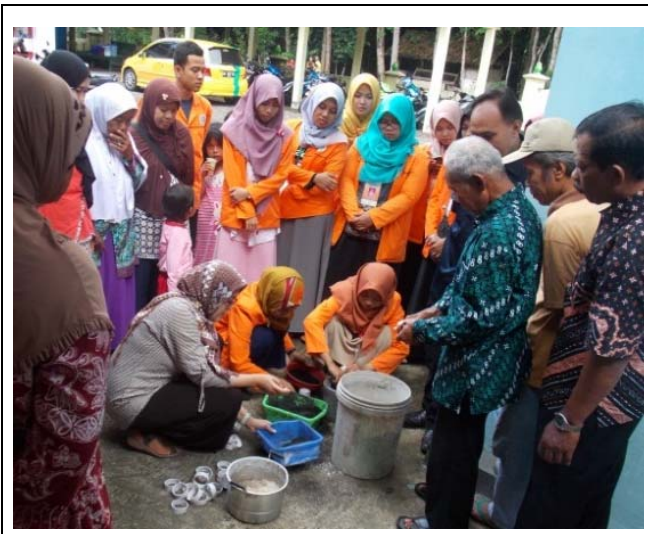

Gambar 3. Praktek pembuatan briket bioarang

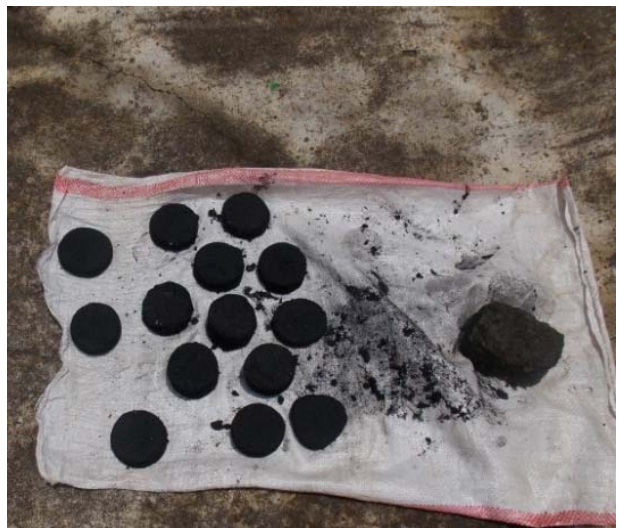

Gambar 4. Produk briket bioarang

Gambar aktivitas mahasiswa KKN UAD dan masyarakat Padukuhan 3 Desa Pandowan dalam program kepedulian masyarakat terhadap lingkungan tersaji pada gambar 4,5,6 dan 7.

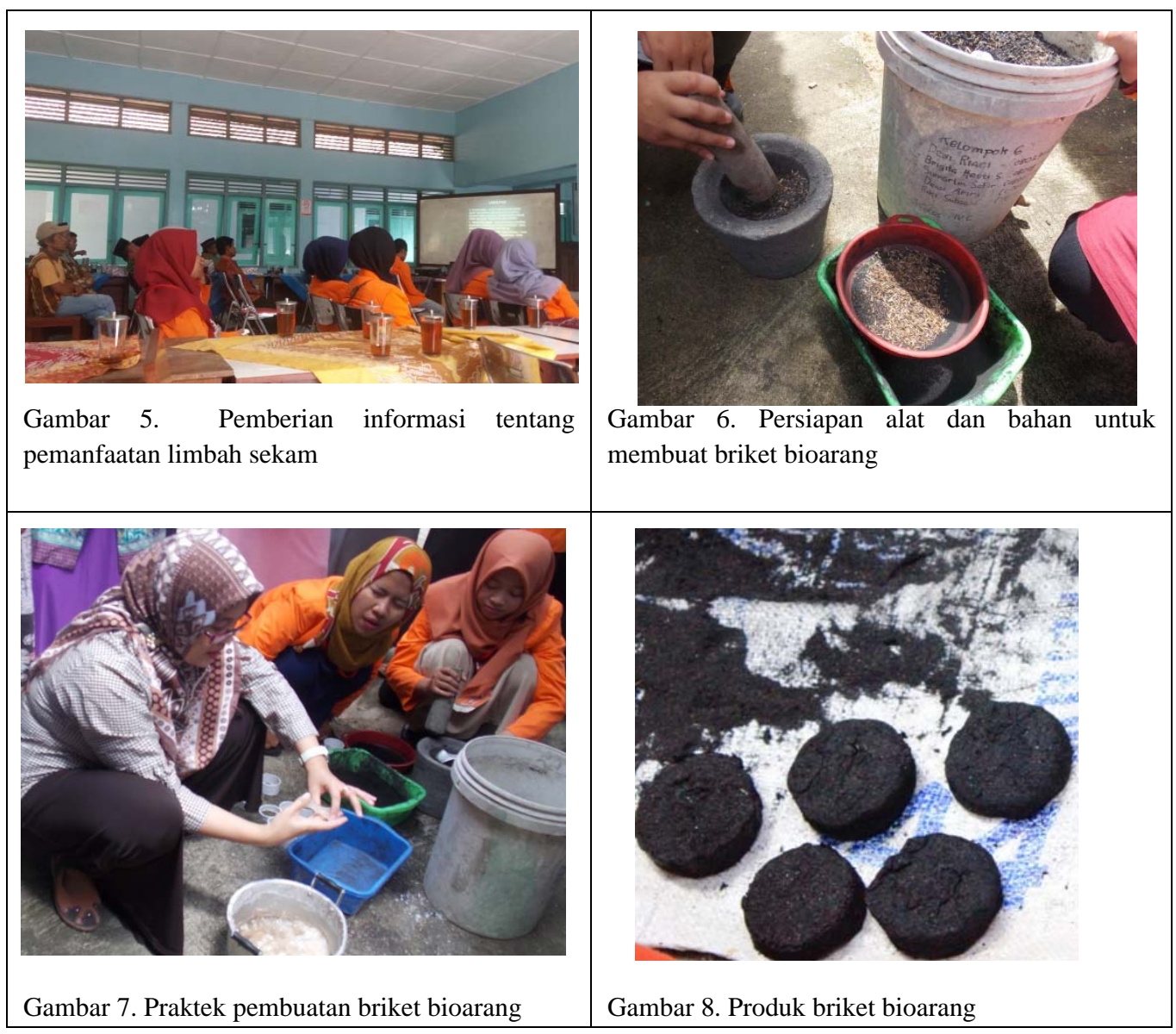


Diterbitkan oleh Lembaga Pengabdian kepada Masyarakat

Universitas Ahmad Dahlan Yogyakarta

Gambar aktivitas mahasiswa KKN UAD dan masyarakat Padukuhan 4 Desa Pandowan dalam program kepedulian masyarakat terhadap lingkungan tersaji pada gambar 9,10, 11 dan 12.

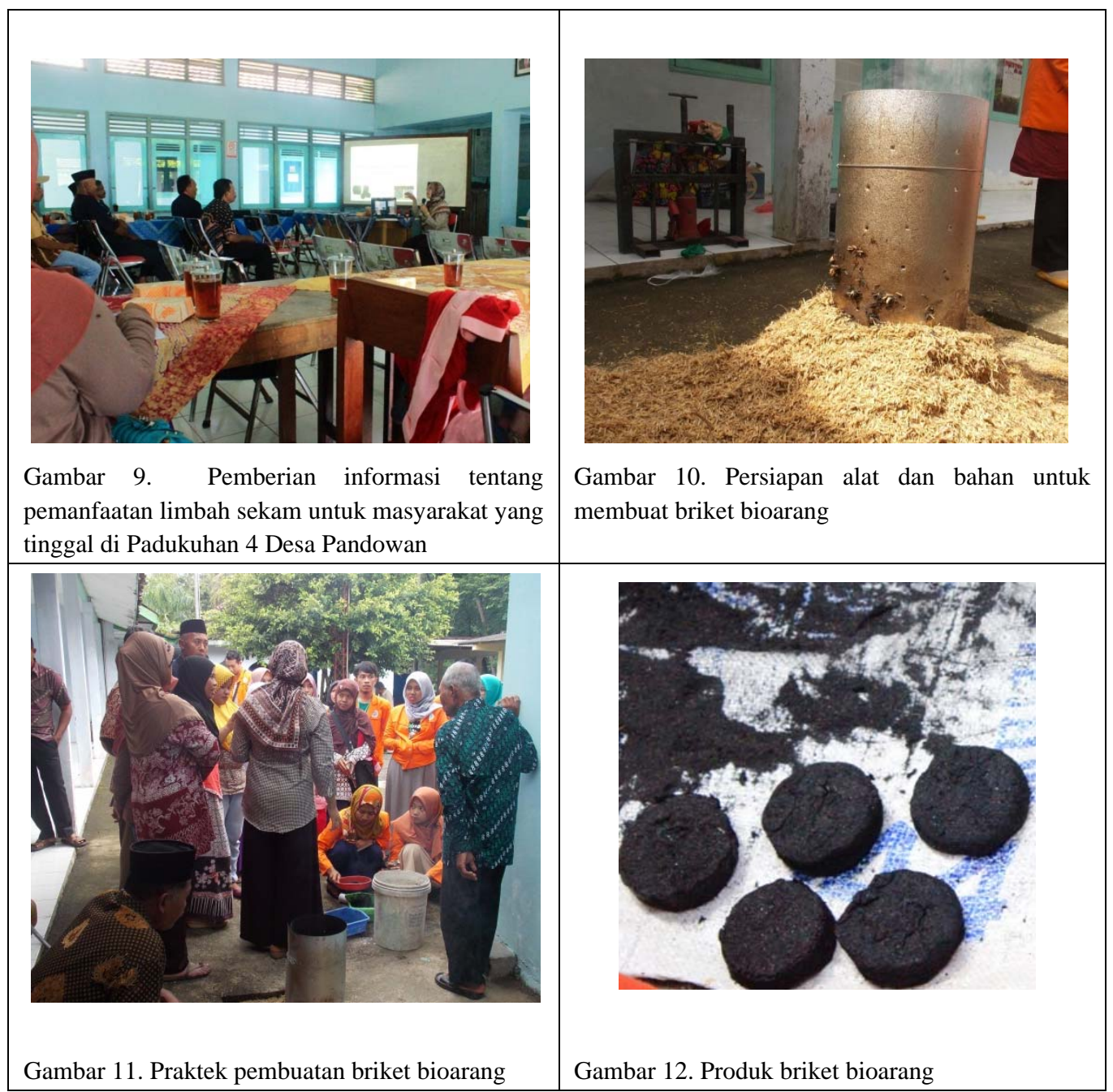

Program kerja pembuatan briket bioarang dilakukan sebagai program kerja tematik KKN Reguler 61 divisi XI.A Universitas Ahmad Dahlan. Pembuatan briket bioarang memanfaatkan limbah pertanian yaitu sekam padi yang jumlahnya melimpah setelah musim panen tiba. Selain sebagai pemanfaatan limbah, kegiatan ini juga bertujuan untuk memberikan informasi pada warga Desa Pandowan keuntungan dari penggunaanbriket bioarang dari sekam padi.

KKN UAD XI.A yang ditempatkan di Desa Pandowan dibagi menjadi 3 Padukuhan dengan setiap unit berjumlah 9 orang. Pada Padukuhan 2 ditempati oleh XI.A.2, Padukuhan 3 (Diren) ditempati oleh XI.A.1, dan Padukuhan 4 (Prembulan) ditempati oleh XI.A.3. Dari masing-masing unit memiliki program kerja tematik yaitu kepedulian 
masyarakat terhadap pengolahan sekam padi untuk menghasilkan bahan bakar bioarang sebagai bahan bakar alternatif.

Warga Desa Pandowan sangat antusias dengan adanya program pembuatan briket bioarang ini, terbukti dengan semangat warga yang ingin melakukan sendiri proses mencetak briket bioarang. Proses pembutan bioarang ini terbilang cukup lama pada saat proses pembakaran sekam dengan uap panas, jika konsistensi panas tidak rata menyebabkan waktu pembakaran menjadi semakin lama. Selain proses pembakaran, roses penjemuran juga membutuhkan waktu yang cukup lama yaitu 2-3 hari dibawah sinar matahari.

Pada mulanya sebelum ada sosialisasi briket bioarang masyarakat tidak mengetahui limbah sekam yang menumpuk saat panen padidapat dioleh menjadi sesuatu yang menguntungkan masyarakat. Biasanya masyarakat menggunakan limbah sekam hanya untuk alas kandang ayam, abu gosok, bahan bakar tungku, dan untuk membakar bata merah, sehingga pemanfaatannya kurang maksimal. Cara memanfaatkan limbah sekam dengan dibakar tersebut justru akan mempengaruhi kualitas udara. Sehingga dengan adanya program yang dilaksanakan oleh KKN UAD XI.A, dapat mengubah pola pikir masyarakat untuk membuat sendiri briket bioarang tanpa mencemari lingkungan sekitar dan membuat bahan bakar alternatif.

Keuntungan yang diperoleh dari penggunaan briket bioarang antara lain adalah biayanya yang murah, alat dan bahan mudah didapat, dan cara pembuatannya yang mudah. Disisi lain penggunaan briket bioarang tidak memberi dampak negatif terhadap lingkungan, justru membuat lingkungan menjadi bersih dan sehat karena memanfaatkan sampah organik dan sekam padi yang semula merupakan limbah.

Secara terperinci banyak keuntungan yang diperoleh jika menggunakan briket bioarang antara lain sebagai berikut:

1. Biaya lebih murah dibandingkan dengan minyak tanah

2. Tidak perlu berkali- kali mengipasi atau menambah dengan bahan bakar yang baru.

3. Briket bioarang memiliki masa bakar jauh lebih lama.

4. Penggunaan briket bioarang relatif lebih aman karena nyalanya ada di tengah tungku dan tidak akan bocor.

5. Briket bioarang mudah disimpan dan dipindahkan-pindahkan.

6. Briket bioarang menghasilkan aroma lebih sedap, baik bagi orang yang menggunakannya maupun bagi masakan yang diolahnya.

\section{KESIMPULAN}

KKN UAD memiliki program dalam memberdayakan masyarakat yaitu pemanfaatan limbahsekam padi yang ada di lingkungan desa Pandowan, Galur, Kulon Progomenjadi briket bioarang yang dapat dijadikan salah satu bahan bakar alternatif. 
Diterbitkan oleh Lembaga Pengabdian kepada Masyarakat

Universitas Ahmad Dahlan Yogyakarta

\section{DAFTAR PUSTAKA}

Pandowan. 2017. Profil Desa Pandowan. Kulon Progo: Balai Desa Pandowan

Himawanto, D. A. 2003. Pengelohan Limbah Pertanian menjadi Biobriket Sebagai Salah Satu Bahan Bakar Alternatif. Laporan Penelitian. Surakarta: UNS

Yuliah, Y, Suryaningsih, S, Ulfi, K, 2017, Penentuan Kadar Air Hilang Dan Volatile Matter Pada Bio-Briket Dari Campuran Arang Sekam Padi Dan Batok Kelapa, Jurnal Ilmu Dan Inovasi Fisika Vol. 01, No. 01 